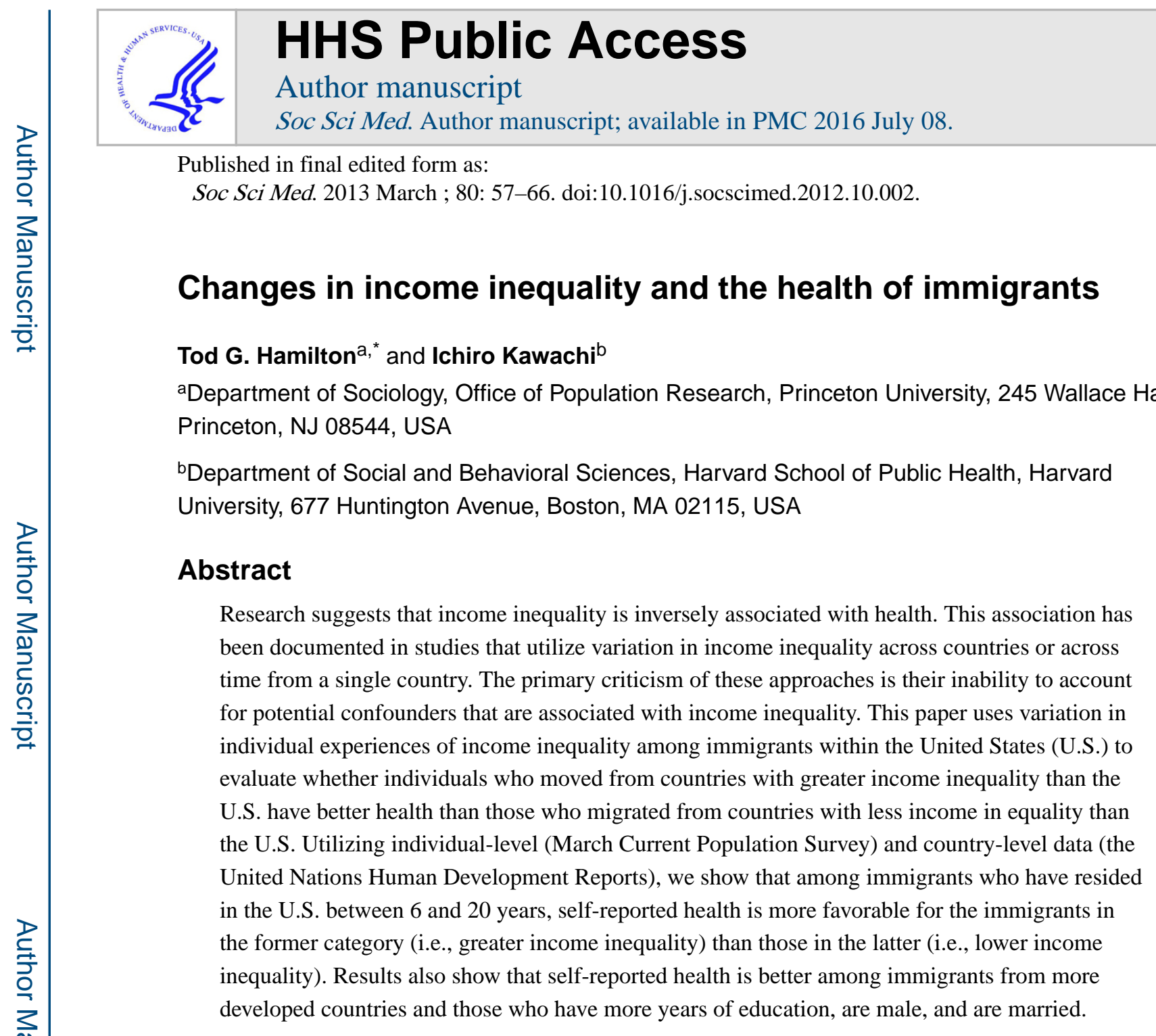

Keywords

United States; Health; Income inequality; Inequality; Immigrants; Migration

\title{
Introduction
}

A large literature suggests that upon arrival in the United States (U.S.) immigrants have a health advantage over members of the native-born population (Antecol \& Bedard, 2006; Cho, Frisbie, Hummer, \& Rogers, 2004; Hummer, Powers, Pullum, Gossman, \& Frisbie, 2007; Hummer, Rogers, Nam, \& LeClere, 1999). These benefits have been documented in almost every domain of health. On average, immigrants are less likely to smoke or drink, self-report lower levels of chronic illnesses, and have lower risk of mortality from almost all causes of death (Abraido-Lanza, Chao, \& Florez, 2005; Abraido-Lanza, Chao, \& Gates, 2005; Akresh, 2007; Angel, Buckley, \& Sakamoto, 2001; Antecol \& Bedard, 2006; Cho et al., 2004; Elo, Mehta, \& Huang, 2011; Hummer, Biegler et al., 1999; Hummer et al., 2007; Hummer, Rogers et al., 1999; Jasso, Massey, Rosenzweig, \& Smith, 2004; Mutchler,

\footnotetext{
*Corresponding author. Tel.:+1 609258 5938, todh@princeton.edu (T.G. Hamilton).
} 
Prakash, \& Burr, 2007; Singh \& Hiatt, 2006; Singh \& Siahpush, 2002). Similar health profiles have been found among immigrants to Canada and Australia (Biddle, Kennedy, \& McDonald, 2007; Newbold, 2005; McDonald \& Kennedy, 2004, 2005).

While research has documented these advantages for most racial and ethnic subgroups of immigrants (Antecol \& Bedard, 2006; Hummer, Biegler et al., 1999; Hummer, Rogers et al., 1999; Jasso et al., 2004), few studies have evaluated the factors that produce variation in health among immigrants. One set of factors that might produce this variation is the conditions in their countries of origin, particularly the level of income inequality. Research suggests that the degree of income inequality faced by individuals in their place of residence is inversely related to health (Kondo et al., 2009; Subramanian \& Kawachi, 2004). However, it is unclear whether individuals can improve their health by migrating from places characterized by greater income inequality to places characterized by less income inequality. For example, much of the work that documents this relationship uses variation in income inequality across countries or across time from a single country rather than changes in inequality experienced by particular individuals.

This paper has two goals. First, we evaluate whether country-level measures of conditions in immigrants' countries of origin impact their post-migration health in the U.S. Second, we improve on current research on the relationship between income inequality and health by evaluating whether immigrants who move from countries with greater income inequality than the U.S. report better health than those who migrate from countries with less income inequality than the U.S.

Utilizing data on immigrants from the 1996, 1998, 2000, 2002, 2004, 2006, and 2008 waves of the March Current Population Survey (CPS) in conjunction with data from the 2009 United Nations Human Development Programme's Human Development Reports, we show that self-reports of health are more favorable among immigrants who are younger, are married, are male, and who have higher levels of education. Models that incorporate country-of-origin characteristics show that immigrants who migrate from countries with greater levels of income inequality report better health than immigrants who migrate from countries with less income inequality. Results also show that immigrants from more developed countries have lower odds of reporting fair/poor health than immigrants from less developed countries.

\section{Background and hypotheses}

\section{Selective migration and health}

Few papers evaluate the factors that produce variation in health among immigrants. One notable exception is Jasso et al. (2004). This seminal paper proposes a theoretical framework that explains the degree of both labor market and health selection among immigrants in the U.S. The primary predictor of variation in health among immigrants within this framework is differences in the price of skills across countries. Holding other factors constant, Jasso et al. argue that immigrants from countries in which the price of skills is relatively high (measured by GDP per capita) should be more selected on health than immigrants from countries in which the price of skills is relatively low. This proposition is based on the 
assumption that health is an important determinant of the amount of labor supplied by individuals and of the level of human capital or skills that individuals are able to acquire. Therefore, because immigrants often move to take advantage of differences in wages (skills prices) across countries, immigrants from countries that have higher skills prices should also report better health than those from countries with lower skills prices.

\section{Income inequality and health}

A growing body of literature has focused on income inequality and its potential effects on population health (Wilkinson \& Pickett, 2010). The central claim made by proponents of this theory is that societies with a more unequal distribution of income pay a penalty in terms of lowered life expectancy, higher rates of stress and mental illness, more crime and imprisonment, and a lowered quality of life (Kawachi \& Kennedy, 2006). In short, a society with greater income inequality tends to have more poor people than a more egalitarian society; poverty is causally linked to worse health outcomes (Kawachi, Adler, \& Dow, 2010); as a result, societies with greater income inequality will tend to exhibit worse population health status, on average, compared to societies with a more egalitarian income distribution. The theory of income inequality and health makes an additional—and more contested—claim: that income inequality adversely affects the health of both the rich and poor members of society. In other words, greater inequality harms everybody's interests, not just the health security of the poor. Within the field of income inequality research, this is referred to as the contextual effect of income inequality on population health (Kawachi, 2000).

Kawachi (2000) puts forward two separate mechanisms to explain this contextual effect, both related to negative externalities and spillover effects of living in a society with an unequal distribution of income. First, from the perspective of those in the top half of the income distribution, living in an unequal society increases their exposure to the "pathologies of poverty," including more crime and violence, and certain infectious diseases (such as multidrug-resistant tuberculosis). In theory, some members of the affluent classes could segregate themselves from undesirable contact with the worse-off members of society-for example, by retreating to gated communities. Nevertheless, the theory posits, the affluent may be unable to completely escape the pathologies of poverty. Conversely, from the perspective of those in the bottom half of the income distribution, living in the presence of very wealthy people exposes them to so-called pecuniary spillover effects. For example, when the wealthy move into communities they often drive up real estate prices, compete for scarce places in classrooms, and eventually spur a rise in property taxes, making the area unaffordable to those with more modest means. A different negative externality is caused by the conspicuous consumption habits of the super affluent, which produce invidious social comparisons and lead to positional competition that is both stressful and socially wasteful (Frank, 1999; Kawachi \& Kennedy, 2006).

Empirical demonstrations of the contextual effect of income inequality have relied upon multilevel analysis (Kondo et al., 2009). In this approach, researchers examine differences in the health achievement of individuals living in different localities characterized by varying degrees of income inequality, adjusting for confounding variables including individual's 
own income. For example, within the U.S., researchers have examined variations in the health status of residents living in different states that are characterized by varying degrees of income distribution (Lynch et al., 2004; Subramanian \& Kawachi, 2004). Kondo et al. (2009) conducted a meta-analysis of multilevel studies that examined the association between income inequality and health. They identified 27 eligible multilevel studies conducted in different countries (e.g., the United States, Europe, New Zealand, China), representing more than 60 million individuals. According to the meta-analysis, each 0.05 unit increase in the Gini coefficient was associated with a roughly $7 \%$ excess risk in allcause mortality in the population. In other words, the pooled evidence on income inequality and health is consistent with the counterfactual scenario whereby individuals can expect to pay a health penalty consisting of a 7\% increase in their mortality risk when moving from a low-inequality locale to a different locale with a 0.05 unit higher Gini coefficient (Kondo et al., 2009). Whether this pooled excess risk represents causality is open to debate, because residual confounding by unobserved characteristics (either at the individual level or the area level) remains a possibility.

Kondo et al. (2009) also noted that the majority of studies conducted to date have considered area variations in income inequality within country borders, e.g., variations in the Gini coefficient among the 50 U.S. states. This design may have constrained the potential range of variation in the Gini coefficient. That is, the U.S. (which is currently the most unequal country in the OECD) features a range of distribution in the Gini coefficient that exhibits little overlap with other countries. For example, a cross-national comparison of income inequality in the U.S. compared to Canada demonstrated that the most egalitarian U.S. state is still more unequal (i.e., has a higher Gini index) compared to the most unequal Canadian province (Ross et al., 2000). Indeed, Ross et al. (2000) show that there is not a significant association between mortality and the level of income inequality within Canada. However, this finding might be the result of the distribution of immigrants within the country (Razum, 2000).

Two types of research strategies could be used to overcome the problem of constrained variation. Either one could examine a large cross-national sample with sufficient variation in income inequality, or one could examine a long time series within a single country and regress changes in health status on changes in income inequality. However, few large datasets exist with these types of information. Beckfield (2004) addresses both of these limitations in a study examining income inequality in 115 countries over the 1947-1996 time period using life expectancy and infant mortality rates as the outcomes. He concludes that there is no evidence of an association between income inequality and life expectancy using a fixed effects analytical approach that controlls for time invariant sources of unobserved heterogeneity.

Although fixed effects approaches are motivated by a concern for addressing unobserved heterogeneity (Beckfield, 2004), the interpretation of the results from such analyses have been debated for two reasons: a) they potentially ignore differences in intermediary variables that might reflect the causal effect of income inequality in a prior time period (e.g., educational investment); and b) the time periods involved in testing change-on-change effects might not reflect realistic or biologically plausible lag times and induction periods for 
income inequality to produce differences in health outcomes (e.g., longevity). In other words, using fixed effects could inappropriately adjust for between-country variations in variables such as educational inequalities that might actually be attributable to inequalities in income distribution prior to the observation period.

An alternative approach for testing the income inequality hypothesis is to examine the change in the health of migrants moving between countries with different levels of income inequality. To our knowledge, no previous study has attempted this design. An analogy can be drawn here to studies within the field of neighborhood contextual effects on health. A growing literature has attempted to demonstrate the contextual effects of different neighborhood environments on the health of residents (Kawachi \& Berkman, 2003). Such studies have employed two types of study designs. The researchers can either attempt to change the neighborhood environment and observe the contemporaneous or lagged changes in the health status of the residents, or they can move residents from their current neighborhood to a different neighborhood and observe subsequent changes in their health status. The latter design is exemplified by the U.S. Housing and Urban Development experiment on residential mobility, the Moving to Opportunity (MTO) Demonstration Program, in which low-income residents were randomly relocated to different neighborhoods based on a voucher program (Kling \& Liebman, 2004).

Our study is analogous to the MTO experiment in that we examine the health status of immigrants who moved to the U.S. from countries characterized by varying degrees of income inequality. Unlike the MTO studies, immigrants are not a random sample of their countries of origin. Immigrants are often selected on hard-to-measure characteristics such as motivation and ambition as well as on measurable characteristics such as education and age. Therefore, we cannot claim that a random individual from a particular country would experience the outcomes demonstrated in this paper. Rather, we show the relationship between income and health among individuals who are selected on characteristics that produce migration.

Although our data are observational (not experimental), they provide a novel test of the income inequality hypothesis. The extant literature suggests that there are health benefits to living in a more equal society (Kawachi \& Kennedy, 2006). Therefore, we conjecture that the health of immigrants from more egalitarian societies than the U.S. (measured by the degree of income inequality) will report worse health in the U.S. because of the negative effects of moving to a more unequal society. Conversely, we conjecture that immigrants from countries with a less egalitarian distribution of income will experience improvements in health as a result of moving to a more egalitarian society (the U.S.).

\section{Data, measures, and methods}

The analytic sample for this paper comes from the 1996, 1998, 2000, 2002, 2004, 2006, and 2008 waves of the March Current Population Survey (CPS) for foreign-born individuals between the ages of 25 and 64 . We define immigrants as individuals who were born outside of the U.S. To avoid including individuals in the sample who are more similar to U.S.-born natives than to immigrants, we exclude anyone born abroad to American parents and those 
born in U.S. outlying areas. Immigrants who have resided in the U.S. for more than 20 years are not included in the study. This restriction is made to avoid assigning recent country-oforigin data to immigrants who have resided in the U.S. for a long time period. Because it has been well-documented that immigrants arrive in the U.S. with better health than the nativeborn population, immigrants who have resided in the U.S. for less than six years are excluded from the sample. This restriction is also made to increase the likelihood that immigrants are comparing their health to individuals in the U.S. rather than to individuals in their countries of origin when they self-report their health status. Immigrants with missing country-of-origin data are excluded from the sample. The final analytic sample comprises 35,620 immigrants.

The analysis in this paper evaluates variation in self-reports of fair/poor health. This variable is generated from the March CPS question that asks respondents to rate their "current health on a five-point scale, as excellent, very good, good, fair, or poor." Data from this question are used to create a dichotomous variable that is equal to 1 if a respondent self-reports his/her health as poor or fair, and 0 otherwise.

The analyses in this paper control for individual-level characteristics that are correlated with health, including age, age squared, and whether an individual is a female. To account for socioeconomic differences among immigrants, regression models include seven dichotomous variables that capture immigrants' levels of education: less than high school, high school, some college, associate's degree, bachelor's degree, master's degree, and graduate degree (e.g., professional school degree or doctorate degree). To account for geographic differences among immigrants, models also control for whether an immigrant resides in a metropolitan area as well as the U.S. region of current residence.

Data from the CPS are well-suited to this study for two reasons. First, these data contain a larger sample of immigrants than other datasets commonly used to study the health of immigrants. Second, these data identify the exact country in which immigrants were born, which makes it possible to merge aggregate-level data to each immigrant observation.

The aggregate country data for this study comes from the 2009 Human Development Reports of the United Nations' Development Programme (http://hdr.undp.org/en/reports/ global/hdr2009/chapters/). The Human Development Reports are a compilation of countrylevel data for every country in the world. These data are used to create measures of overall human well-being within countries, such as the Human Development Index. This paper extracts four broad variables from these data, including the combined gross enrollment ratio for primary, secondary, and tertiary education; gross domestic product (GDP) per capita; life expectancy at birth; and the Gini index (Gini coefficient $\times 100$ ).

The combined gross enrollment ratio variable is designed to capture basic education conditions within a country. It ranges from 0 to 100 , with a value of 0 meaning that no school-aged children are enrolled in school and a value of 100 meaning that all school-aged children within a country are enrolled. GDP per capita serves as a measure of a country's overall level of development. The life expectancy at birth variable serves as a summary measure of health conditions within a country. The Gini index is used to capture differences 
in income inequality across countries. This measure ranges from 0 to 100 . A Gini index of 0 represents perfect income equality within a country, whereas a value of 100 depicts perfect inequality.

The 2009 Human Development Reports record the 2007 values of each of these measures. Consequently, this study assigns 2007 country-of-origin data to every immigrant who appears in CPS waves between 1996 and 2008. This procedure would introduce measurement error if the relative position of countries were to change dramatically across the survey years. However, the relative position among most countries has remained fairly stable over the last 20 years.

\section{Health models}

Equation (1) represents our baseline regression:

$$
\text { Health }_{i}=X_{i} \delta+T_{i} \phi+R_{i} \varphi+H_{i} \eta+\varepsilon_{i}
$$

This equation represents logistic regression models of fair/poor health status. In these models, the vector $X$ includes controls for age, age squared, gender, marital status, education, whether an immigrant resides in a metropolitan area, and the U.S. region of current residence. $T$ is a vector of dummy variables indicating the survey year. $R$ is a vector of dummy variables that identifies immigrants' regions of birth. $H$ is a vector that includes GDP per capita; life expectancy at birth; the combined gross enrollment ratio for primary, secondary, and tertiary education; and the Gini index.

The key country-of-origin variable in this study is the Gini index. As such, we estimate three sets of models to evaluate the impact of income inequality on the health of immigrants. First, models are estimated where the Gini index enters the models linearly. These models evaluate the direction of the relationship between health and income inequality among immigrants. Second, to evaluate the impact of moving from a country with greater income inequality than the U.S., the Gini index is replaced by a variable that equals 1 if immigrants migrated from a country with a greater Gini index than that of the U.S. (40.8) and 0 otherwise. Third, to determine whether the results are sensitive to other cut-points, models are estimated where the Gini index is separated into four categorical variables: less than 30, greater than or equal to 30 and less than 40 , greater than or equal to 40 and less than 50 , and greater than or equal to 50 .

\section{Results \\ Descriptive results}

Table 1 shows descriptive statistics for the sample. The first row shows the proportion of respondents who report fair/poor health by race/ethnicity. White immigrants have the smallest proportion (0.07) of respondents who report fair/poor health. After this group, the proportion of immigrants reporting fair/poor health is smallest among black (0.09) and Asian (0.09) immigrants. Hispanic immigrants have the greatest proportion of respondents who report fair/poor health (0.10). 
Table 1 also shows considerable variation in social and demographic characteristics among immigrants. For example, the mean age of white, black, and Asian immigrants is approximately 41 years. In contrast, the mean age of Hispanic immigrants is 37 . Moreover, relative to the other subgroups, a greater share of Hispanic immigrants are male. Table 1 also shows differences in education among the four racial/ethnic groups. Columns 1 and 4 show that white and Asian immigrants have the greatest mean years of schooling within the immigrant sample at 14.21 and 14.11 years, respectively. After these two groups, black immigrants have the greatest mean years of schooling (13.36). Hispanic immigrants have the lowest mean years of schoolings (10.58).

Variation also exists in region of current residence among immigrants. Columns 1 and 2 show that $35 \%$ of white immigrants and $51 \%$ of black immigrants reside in the Northeast. In comparison, $50 \%$ of Hispanic immigrants and $45 \%$ of Asian immigrants reside in the western region of the U.S. Table 1 also shows that while over $90 \%$ of all immigrants reside in metropolitan areas, the percentage of black immigrants who reside in metropolitan areas (98\%) is greater than that of any other subgroup of immigrants.

Table 2 shows descriptive statistics by region of birth for immigrants. Row 1 of this table shows that immigrants who comprise the residual group (Other) have the smallest percentage of respondents who report fair/poor health. After this group, North American (0.06), African (0.07), and European (0.07) immigrants have the next best reports of health. For the West Indies, 14\% of immigrants report their health as fair/poor, the highest percentage of all the immigrant groups.

Considerable differences in education exist among the regional subgroups of immigrants. With the exception of immigrants who comprise the residual category, the most educated subgroups of immigrants tend to migrate from North America, Africa, Europe, and Asia, with roughly 14 mean years of schooling each. Central American and West Indian immigrants have the lowest mean years of schooling at 10.26 and 12.09 , respectively.

The primary objective of this paper is to evaluate the health implications of migrating to a country with a different level of income inequality than that faced by immigrants in their countries of origin. Thus, it is important to demonstrate that other country-level measures that are correlated with income inequality, such as GDP per capita and life expectancy at birth, are not driving the results. To evaluate this possibility, Table 3 shows the distribution of the four country-level measures used in this paper. The table is sorted by the level of income inequality within each country measured by the Gini index.

Column 2 shows that Japan has the lowest level of income inequality among the countries in this sample (24.90). In contrast, Colombia has the greatest income inequality (58.50). Table 3 also shows considerable variation in GDP per capita, life expectancy at birth, and in the combined gross enrollment ratio among countries with similar levels of income inequality. For example, the Gini index for Ethiopia is 29.80. Ethiopia also has a GDP per capita of 779 , a life expectancy at birth of 54.70, and a combined enrollment ratio of 49. Similar to Ethiopia, Germany has a Gini index of 28.30. In contrast, Germany has a GDP per capita of 34,401 , a life expectancy at birth of 79.80 , and a combined enrollment ratio of 88 . Indeed, 
among countries with Gini indices in the 30s, 40s, and 50s, similar variation exists. This variation bodes well for our analysis of the relationship between income inequality and health.

\section{Regression results}

Table 4 shows odds ratios from logistic regression models of fair/poor health. Columns 1 and 2 show the association between individual-level characteristics and fair/poor health for immigrants. As expected, these models show that older immigrants have greater odds of reporting fair/poor health. Similarly, relative to males, female immigrants also have greater odds of reporting fair/poor health. Model 2 also demonstrates that the immigrant sample exhibits the well-documented inverse association between fair/poor health and education. Relative to immigrants with less than a high school education, immigrants with a high school education have only 0.72 odds of reporting fair/poor health. Similarly, relative to immigrants with a graduate degree, immigrants with just a high school education have more than three times the odds of reporting fair/poor health.

Columns 3 through 8 of Table 4 evaluate the impact of the level of income inequality in immigrants' countries of origin on their post-migration health in the U.S. Column 3 of this table shows that prior to controlling for other country-of-origin characteristics, the Gini index of immigrants' countries of origin has no statistical impact on immigrants' individual health. However, when either the logarithm of GDP per capita (model 4), the logarithm of life expectancy at birth (model 5), or the combined gross enrollment ratio in education (model 6) variables are included, the odds ratios on the Gini indices are less than 1 and statistically significant. Indeed, in each of these models, all of the country-level characteristics are statistically significant. This suggests that when anchored on another country-level measure, migrating from a country with a greater level of income inequality reduces the odds of reporting fair/poor health among immigrants. Additionally, the results in Columns 4 through 6 suggest that, controlling for individual-level characteristics as well as the level of income inequality in immigrants' countries of birth, immigrants from more developed countries, immigrants from countries with a greater proportion of school-aged children enrolled in schools, and immigrants from countries with a greater life expectancy at birth have smaller odds of reporting fair/poor health.

Column 7 of Table 4 evaluates whether the impact of income inequality holds when each of the country measures are included in a single regression model. In this model, only the odds ratios on the Gini index and the natural logarithm of GDP per capita remain statistically significant. Collectively, the results in Columns 2 through 7 highlight an important point. Greater income inequality in immigrants' countries of origin is statistically associated with lower odds of reporting fair/poor health among individual immigrants in the U.S. However, because a greater Gini index could signal greater income inequality in a relatively rich country or greater inequality in a relatively poor country, the effect of greater income inequality must be conditioned on some other country-level measure of the overall level of development.

Because the health of immigrants is most likely impacted by other unobserved regional differences among immigrants—such as cultural and social backgrounds, health care 
systems, and language in countries of origin-model 8 tries to capture this unobserved heterogeneity by incorporating region-of-birth fixed effects. As Column 8 shows, the magnitude of the income inequality effect increases and the odds ratio on the natural logarithm of GDP per capita becomes more significant. This result suggests that when relevant individual- and country-level characteristics are held constant, immigrants from more developed countries and those from countries with greater income inequality selfreport lower odds of fair/poor health than immigrants from less developed countries and immigrants from countries with less income inequality.

Table 5 directly evaluates the proposition that migrating from a country with greater income inequality than the U.S. is associated with better post-migration health than migrating from a country with less income inequality than the U.S. This is done by replacing the Gini index (a continuous measure) with a variable that is equal to 1 if an immigrant migrates from a country with a greater Gini index than that of the U.S. and 0 otherwise. Unlike the results in Table 4, Column 1 of Table 5 shows that immigrants who migrate from countries with greater income inequality than that of the U.S. have 0.762 the odds of reporting fair/poor health as immigrants from countries with less income inequality than that of the U.S. Column 2 shows that this effect holds after controlling for unobserved region-of-birth differences among immigrants.

Models 3 and 4 in Table 5 evaluate the impact of adding the other country-of-origin variables to the regression models. Relative to model 2, model 3 shows that controlling for the other country measures slightly decreases the independent impact of migrating from a country with a relatively high Gini index. This model shows that, relative to immigrants from countries with lower Gini indices, those from countries with higher Gini indices have 0.743 odds of reporting fair/poor health. Similar to the models presented in Table 4, when all the country measures are added to the model, the high Gini index variable remains statistically significant. Moreover, the fully specified model in Column 4 of Table 5 shows that controlling for region of birth and the other country measures reduces the odds ratio on the high Gini index from 0.762 to 0.641 .

To determine whether the results contained in Table 5 are sensitive to other cut-points, Table 6 shows results from models where the Gini index is separated into four categorical variables: less than 30 , greater than or equal to 30 and less than 40 , greater than or equal to 40 and less than 50, and greater than or equal to 50 . These sensitivity analyses confirm the results presented in Table 5. The results suggest that immigrants who migrated from countries at either of the two lower cut-points have greater odds of reporting fair/poor health than immigrants from countries with Gini indices that are greater than that of the U.S. These results also show that the relationship between income inequality and immigrant health is not strictly linear. That is, there is no statistically significant difference in health between immigrants from countries with Gini indices less than 30 and those from countries with Gini indices greater than 30 and less than 40 . 


\section{Conclusion}

Research suggests that the level of income inequality in a country adversely impacts individual-level health (Kawachi \& Kennedy, 1999). However, one of the primary criticisms regarding such studies is that they do not clearly demonstrate the mechanism by which the level of income inequality impacts health. Most studies in this literature utilize sources of variation in income inequality across countries, within a country, and across time (Beckfield, 2004; Kawachi \& Kennedy, 1999; Kondo et al., 2009). In the current study, we argue that immigrants to the U.S. provide another avenue by which to study the impact of income inequality on health. We do so by examining variation in immigrants' exposure to the income distributions of two countries - their country of birth and the U.S. Specifically, we conjecture that immigrants who migrated to the U.S. from countries with greater income inequality than the U.S. experience an improvement in health because they migrated to a country with lower income inequality. Conversely, we postulate that immigrants from countries characterized by less income inequality than the U.S. experience erosion in health. To our knowledge, this paper is the first to utilize variation in immigrants' exposure to income inequality to test the impact of income inequality on health.

The results demonstrate that moving from a less egalitarian country to a more egalitarian country is associated with better health. Specifically, we find that net of individual- and country-level characteristics, immigrants from countries with greater income inequality than the U.S. have lower odds of reporting fair/poor health than those from countries with less income inequality than in the U.S. This result becomes more pronounced after controlling for the country-of-origin's overall level of development (GDP per capita), life expectancy at birth, combined gross enrollment ratio in education, and region-of-birth fixed effects.

This study has several limitations. It is well-documented that immigrants are not a random sample of the population of their countries of origin. Therefore, we cannot say that a random immigrant can move to a more egalitarian society and experience an improvement in health. Instead, the results suggest that within a population that is selected on factors that produce favorable health outcomes, those who move to a more egalitarian society report better health than those who migrate to a less egalitarian society. Despite this drawback, the quasiexperimental nature of this design is an improvement over previous studies. The most salient criticism within this literature is the use of cross-national or times-series variation in income inequality. In particular, these approaches do not clearly isolate whether change in income inequality is indeed the mechanism driving the results. For example, in a cross-national study where the country is the unit of observation, a negative association between the Gini coefficient and some country-level measure of good health suggests that countries with greater income inequality have worse population health than countries with less income inequality. However, this approach does not illuminate the underlying process that is producing the result. Although this study also does not highlight the exact mechanism that generates the results, it does narrow the range of potential confounders. The current study controls for individual characteristics that impact health as well as country-level factors that are theorized to produce variation in health among immigrants. 
Nevertheless, our results might be driven by some factor that is highly correlated with moving from a more unequal country. For example, countries with more income inequality than the U.S. are often poorer and have poorer population health than the U.S. However, to some extent, this shortcoming is addressed by controlling for measures of overall development (GDP per capita and the combined gross enrollment ratio in education) and the overall population health (life expectancy at birth). Additionally, this criticism would be a great concern if income inequality and a country's population health or level of development were extremely correlated. Our descriptive results show considerable variation in population health among countries with varying levels of income inequality.

This paper also suggests avenues for future work on the association between income inequality and health. The current study exploits variation in health among immigrants who experience the impact of income distributions in two countries. One potential area for future work is to examine changes in the degree of income inequality faced by individuals who move within countries. For example, research suggests that the degree of income inequality within the U.S. is greater than the inequality between the U.S. and other countries (Ross et al., 2000). Moreover, a large degree of income inequality likely exists within immigrants' sending countries. Consequently, another avenue for future research is the examination of the health implications of moving from particular regions within one country to regions within another country that have varying levels of income inequality.

\section{References}

Abraido-Lanza AF, Chao MT, Florez KR. Do healthy behaviors decline with greater acculturation? Implications for the Latino mortality paradox. Social Science \& Medicine. 2005; 61(6):1243-1255. [PubMed: 15970234]

Abraido-Lanza AF, Chao MT, Gates CY. Acculturation and cancer screening among Latinas: results from the National Health Interview Survey. Annals of Behavioral Medicine. 2005; 29(1):22-28. [PubMed: 15677297]

Akresh IR. Dietary assimilation and health among Hispanic immigrants to the United States. Journal of Health and Social Behavior. 2007; 48(4):404-417. [PubMed: 18198687]

Angel JL, Buckley CJ, Sakamoto A. Duration or disadvantage? Exploring nativity, ethnicity, and health in midlife. Journals of Gerontology Series B: Psychological Sciences and Social Sciences. 2001; 56(5):S275-S284.

Antecol H, Bedard K. Unhealthy assimilation: why do immigrants converge to American health status levels? Demography. 2006; 43(2):337-360. [PubMed: 16889132]

Beckfield J. Does income inequality harm health? New cross-national evidence. Journal of Health and Social Behavior. 2004; 45(3):231-248. [PubMed: 15595505]

Biddle N, Kennedy S, McDonald JT. Health assimilation patterns amongst Australian immigrants. The Economic Record. 2007; 83:16-30.

Cho Y, Frisbie WP, Hummer RA, Rogers RG. Nativity, duration of residence, and the health of Hispanic adults in the United States. International Migration Review. 2004; 38(1):184-211.

Elo I, Mehta N, Huang C. Disability among native-born and foreign-born blacks in the United States. Demography. 2011; 48(1):241-265. [PubMed: 21369873]

Frank, RH. Luxury fever: why money fails to satisfy in an era of excess. New York: Free Press; 1999.

Hummer RA, Biegler M, De Turk PB, Forbes D, Frisbie WP, Hong Y, et al. Race/ethnicity, nativity, and infant mortality in the United States. Social Forces. 1999; 77(3):1083-1117.

Hummer RA, Powers DA, Pullum SG, Gossman GL, Frisbie WP. Paradox found (again): infant mortality among the Mexican-origin population in the United States. Demography. 2007; 44(3): 441-457. [PubMed: 17913005] 
Hummer RA, Rogers RG, Nam CB, LeClere FB. Race/ethnicity, nativity, and U.S. adult mortality. Social Science Quarterly (University of Texas Press). 1999; 80(1):136-153.

Jasso, G.; Massey, DS.; Rosenzweig, MR.; Smith, JP. Immigrant health, selectivity and acculturation. In: Anderson, NB.; Bulatao, RA.; Cohen, B., editors. Critical perspectives on racial and ethnic differences in health in late life. Washington DC: National Academy Press; 2004. p. 227-266.

Kawachi, I. Income inequality and health. In: Berkman, LF; Kawachi, I., editors. Social epidemiology. New York: Oxford University Press; 2000. p. 76-94.

Kawachi, I.; Berkman, LF. Neighborhoods and health. Oxford, New York: Oxford University Press; 2003.

Kawachi I, Adler NE, Dow WH. Money, schooling, and health: mechanisms and causal evidence. Annals of the New York Academy of Sciences. 2010; 1186(1):56-68. [PubMed: 20201868]

Kawachi I, Kennedy BP. Income inequality and health: pathways and mechanisms. Health Services Research. 1999; 34(1 Pt 2):215-227. [PubMed: 10199670]

Kawachi, I.; Kennedy, BP. The health of nations: why inequality is harmful to your health. New York: New Press; 2006.

Kling, JR.; Liebman, JB. Moving to opportunity and tranquility: neighborhood effects on adult economic self-sufficiency and health from a randomized housing voucher experiment. Cambridge, MA: Harvard University, John F. Kennedy School of Government; 2004.

Kondo N, Sembajwe G, Kawachi I, van Dam RM, Subramanian SV, Yamagata Z. Income inequality, mortality, and self rated health: meta-analysis of multilevel studies. British Medical Journal. 2009; 339:b4471. [PubMed: 19903981]

Lynch J, Smith GD, Harper S, Hillemeier M, Ross N, Kaplan GA, et al. Is income inequality a determinant of population health? Part 1. A systematic review. Milbank Quarterly. 2004; 82(1):599. [PubMed: 15016244]

McDonald JT, Kennedy S. Insights into the "healthy immigrant effect": health status and health service use of immigrants to Canada. Social Science \& Medicine. 2004; 59(8):1613-1627. [PubMed: 15279920]

McDonald JT, Kennedy S. Is migration to Canada associated with unhealthy weight gain? Overweight and obesity among Canada's immigrants. Social Science \& Medicine. 2005; 61(12):2469-2481. [PubMed: 15972242]

Mutchler JE, Prakash A, Burr JA. The demography of disability and effects of immigrant history: older Asians in the United States. Demography. 2007; 44:251-263. [PubMed: 17583304]

Newbold KB. Self-rated health within the Canadian immigrant population: risk and the healthy immigrant effect. Social Science \& Medicine. 2005; 60(6):1359-1370. [PubMed: 15626530]

Razum O. Income inequality and mortality in Canada and the United States. Low mortality in Canadian cities may be driven by low mortality in immigrants. British Medical Journal. 2000; 321(7275):1533-1534. [PubMed: 11189697]

Ross NA, Wolfson MC, Dunn JR, Berthelot JM, Kaplan GA, Lynch JW. Relation between income inequality and mortality in Canada and in the United States: cross sectional assessment using census data and vital statistics. British Medical Journal. 2000; 320(7239):898-902. [PubMed: 10741994]

Singh GK, Hiatt RA. Trends and disparities in socioeconomic and behavioural characteristics, life expectancy, and cause-specific mortality of native-born and foreign-born populations in the United States, 1979-2003. International Journal of Epidemiology. 2006; 35(4):903-919. [PubMed: 16709619]

Singh GK, Siahpush M. Ethnic-immigrant differentials in health, behaviors, morbidity, and causespecific mortality in the United States: an analysis of two national data bases. Human Biology. 2002; 74(1):83-109. [PubMed: 11931581]

Subramanian SV, Kawachi I. Income inequality and health: what have we learned so far? Epidemiologic Reviews. 2004; 26(1):78-91. [PubMed: 15234949]

Wilkinson, RG.; Pickett, K. The spirit level: Why greater equality makes societies stronger. New York, NY: Bloomsbury Press; 2010. 


\section{로을}

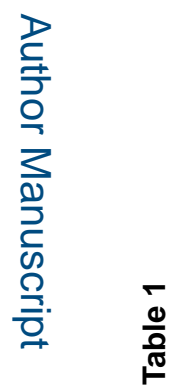

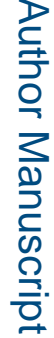

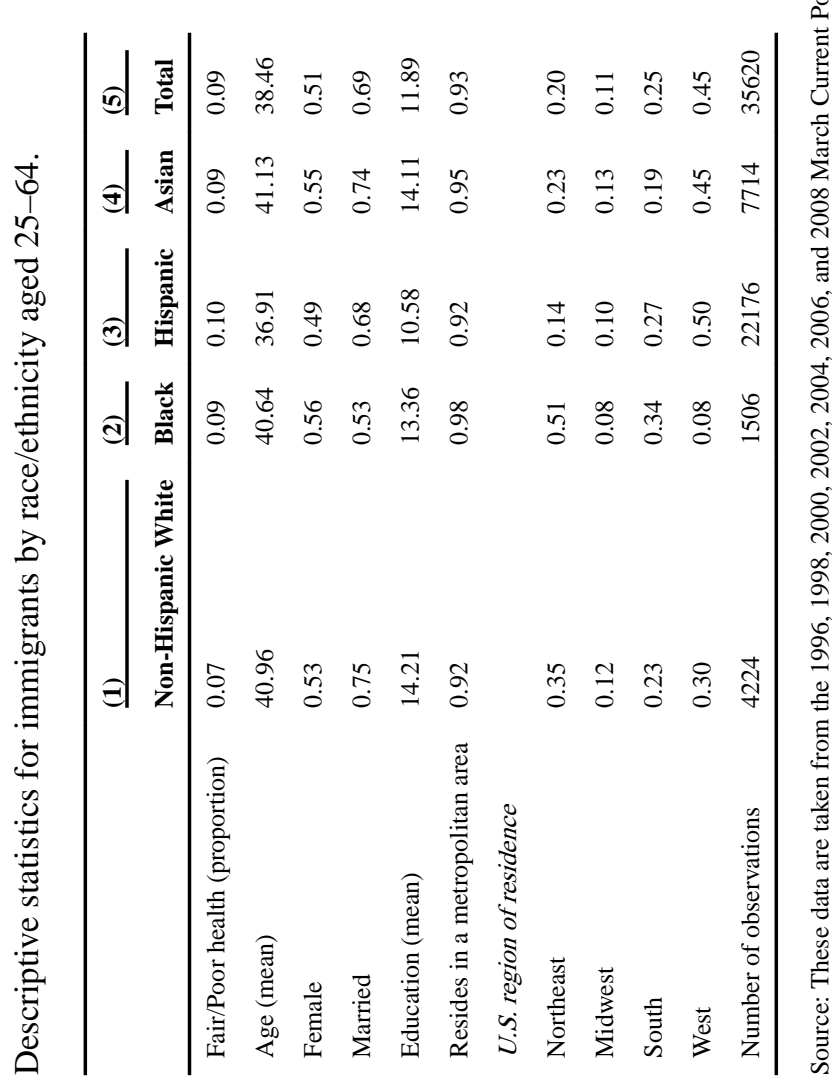

Soc Sci Med. Author manuscript; available in PMC 2016 July 08. 


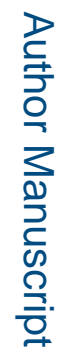

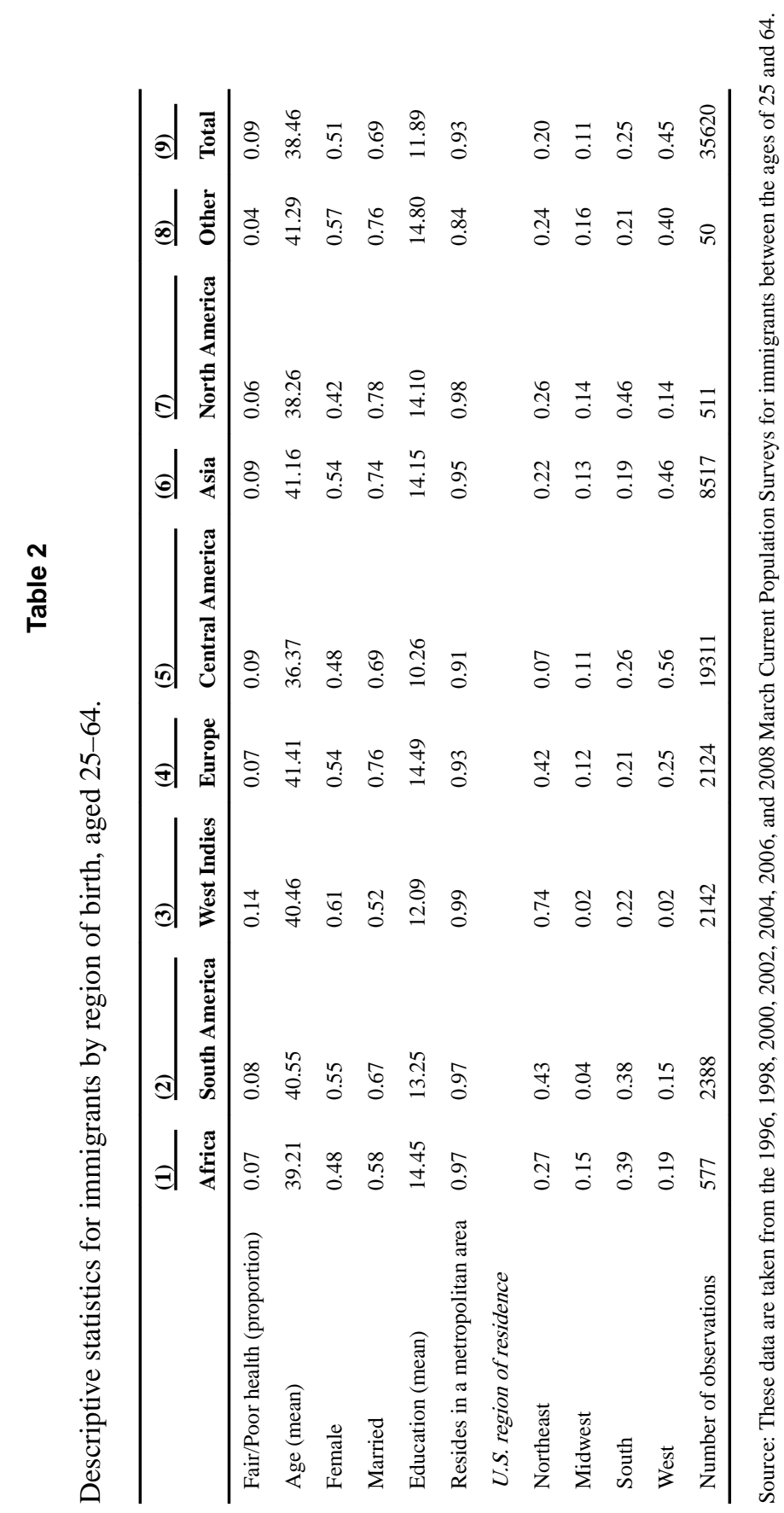

Soc Sci Med. Author manuscript; available in PMC 2016 July 08. 


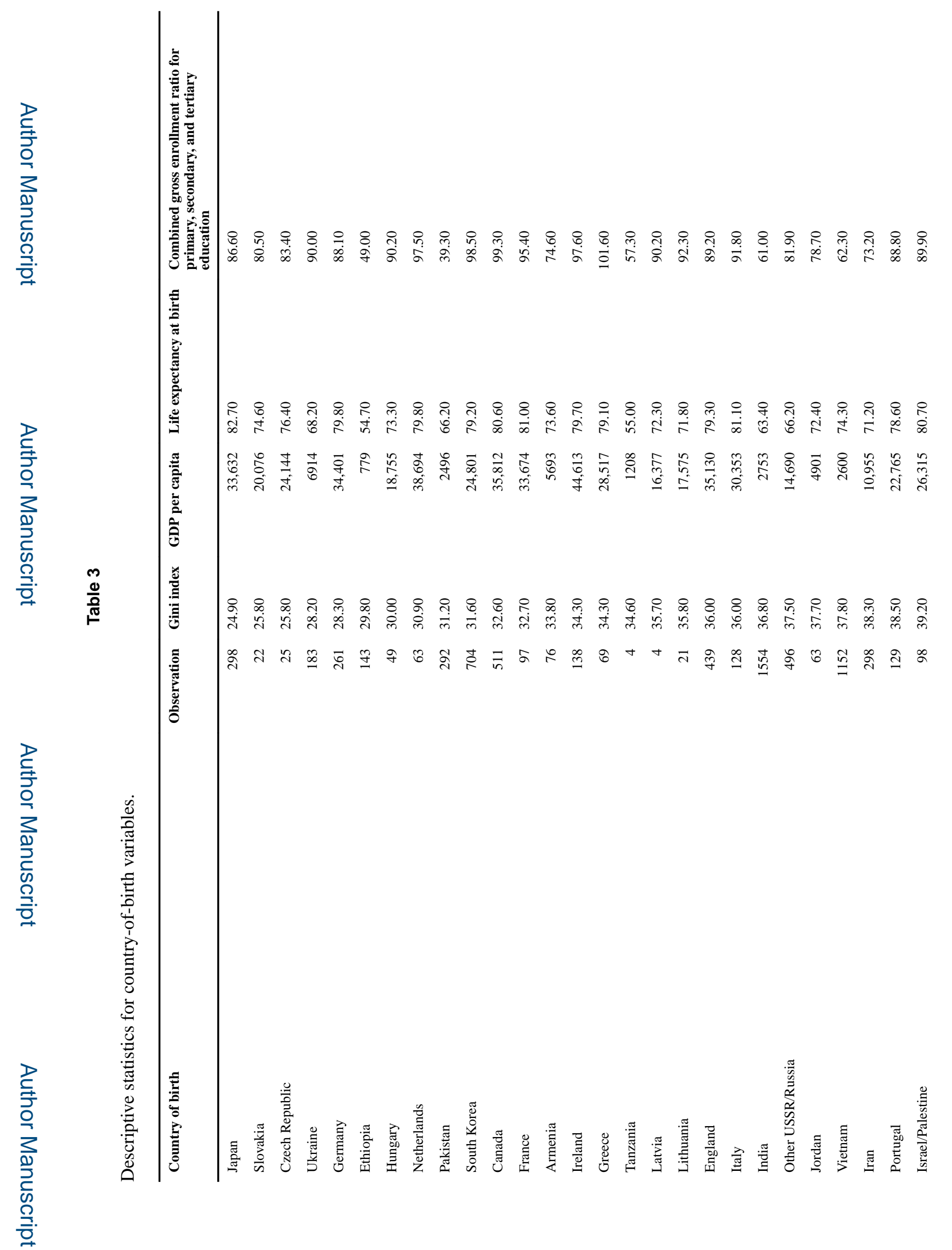

Soc Sci Med. Author manuscript; available in PMC 2016 July 08. 
Hamilton and Kawachi

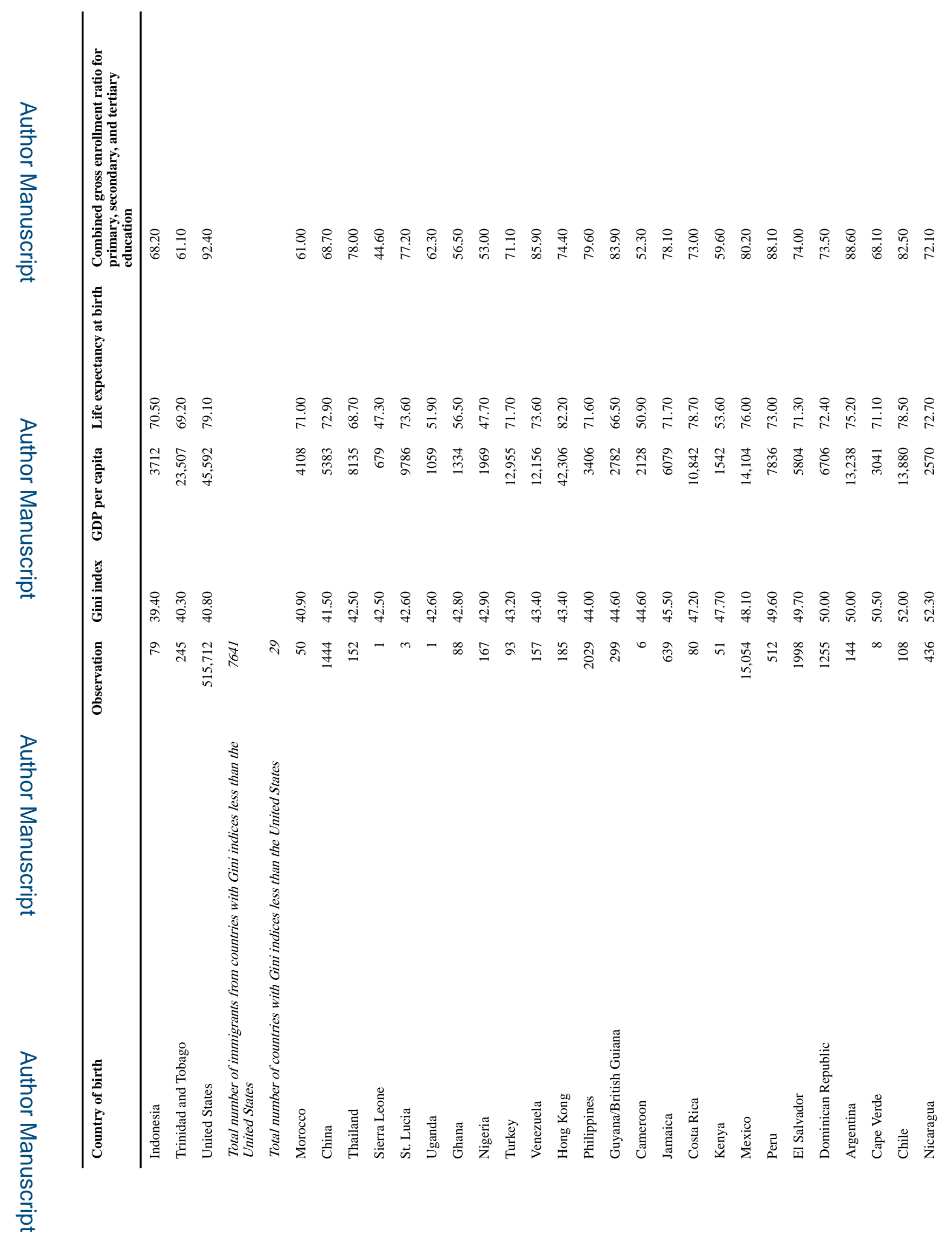

Soc Sci Med. Author manuscript; available in PMC 2016 July 08. 


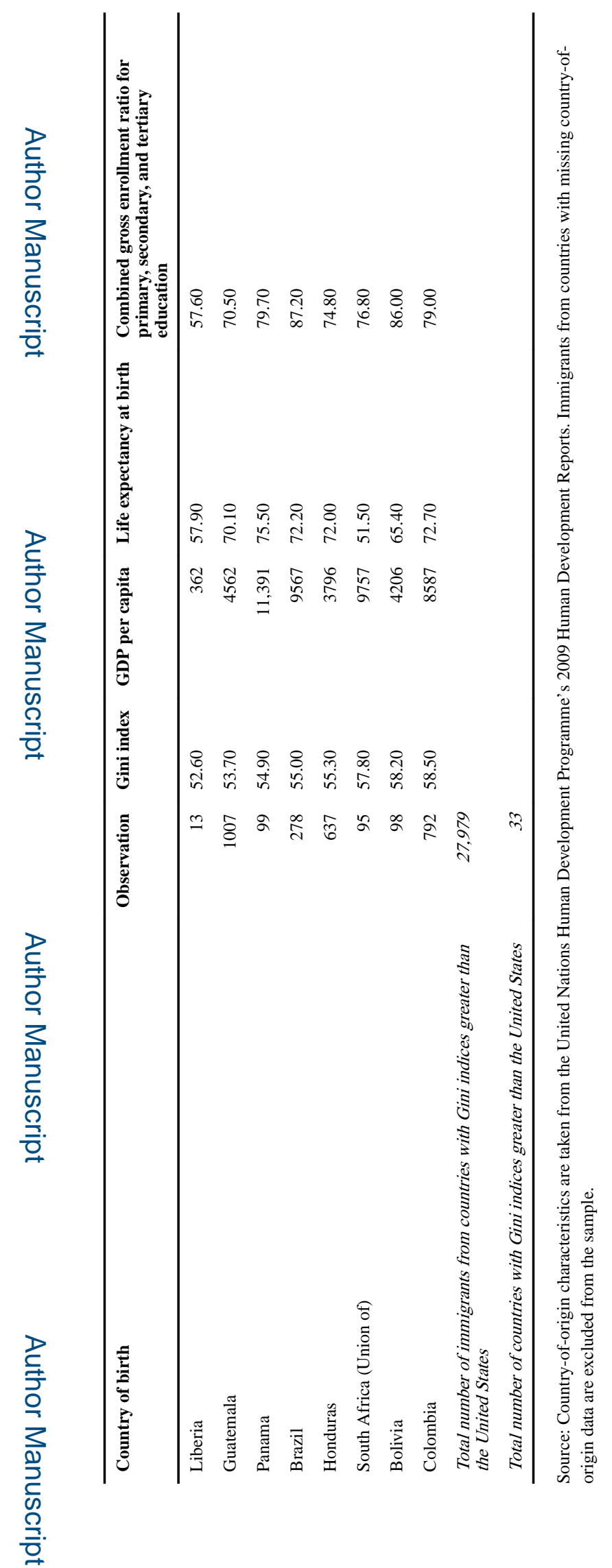

Soc Sci Med. Author manuscript; available in PMC 2016 July 08. 


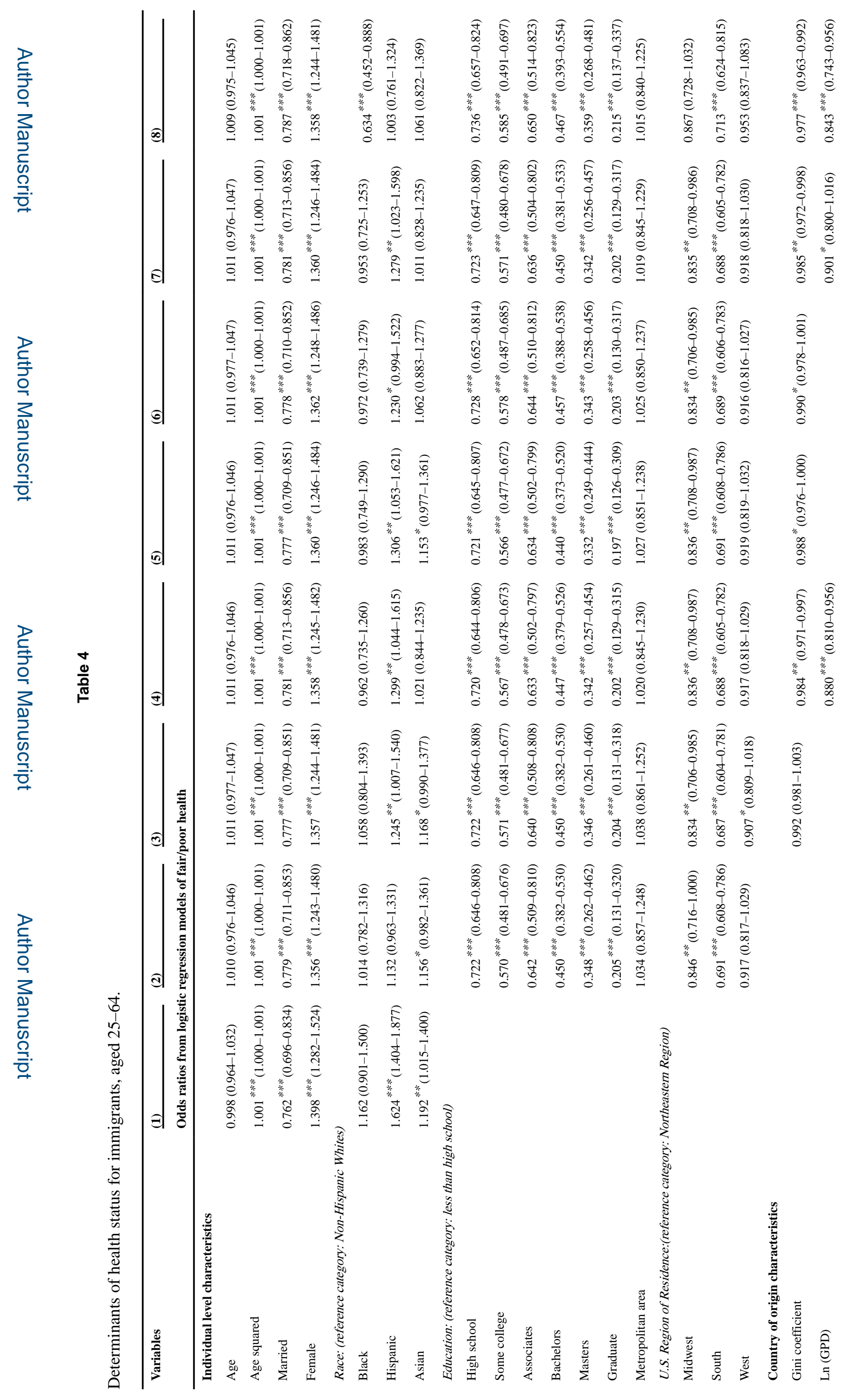




$$
4
$$




\section{Table 5}

Determinants of health status for immigrants, aged 25-64.

\begin{tabular}{|c|c|c|c|c|}
\hline \multirow[t]{2}{*}{ Variables } & $\underline{(1)}$ & $\underline{(2)}$ & (3) & \multirow[t]{2}{*}{ (4) } \\
\hline & \multicolumn{3}{|c|}{ Odds ratios from logistic regression models of fair/poor health } & \\
\hline \multicolumn{5}{|l|}{ Individual level characteristics } \\
\hline Age & $1.012(0.977-1.047)$ & $1.010(0.976-1.046)$ & $1.011(0.977-1.047)$ & $1.009(0.975-1.045)$ \\
\hline Age squared & $1.001^{* * * *}(1.000-1.001)$ & $1.001^{* * * *}(1.000-1.001)$ & $1.001^{* * * *}(1.000-1.001)$ & $1.001^{* * *}(1.000-1.001)$ \\
\hline Married & $0.777^{* * * *}(0.709-0.851)$ & $0.782^{* * * *}(0.714-0.857)$ & $0.782^{* * * *}(0.714-0.857)$ & $0.789^{* * * *}(0.720-0.864)$ \\
\hline Female & $1.359^{* * * *}(1.245-1.483)$ & $1.362^{* * * *}(1.249-1.486)$ & $1.360^{* * * *}(1.246-1.484)$ & $1.360^{* * *}(1.246-1.483)$ \\
\hline \multicolumn{5}{|l|}{$\begin{array}{l}\text { Race: (reference category: Non- } \\
\text { Hispanic Whites) }\end{array}$} \\
\hline Black & $1.178(0.889-1.563)$ & $0.742 *(0.533-1.032)$ & $1.072(0.803-1.430)$ & $0.702^{* *}(0.504-0.979)$ \\
\hline Hispanic & $1.401^{* * * *}(1.139-1.724)$ & $1.062(0.804-1.403)$ & $1.367^{* * * *}(1.103-1.695)$ & $1.037(0.786-1.370)$ \\
\hline Asian & $1.241^{* *}(1.047-1.472)$ & $1.201(0.938-1.538)$ & $1.100(0.896-1.350)$ & $1.158(0.900-1.489)$ \\
\hline \multicolumn{5}{|l|}{$\begin{array}{l}\text { Education: (reference category: } \\
\text { less than high school) }\end{array}$} \\
\hline High school & $0.716^{* * * *}(0.640-0.801)$ & $0.731^{* * * *}(0.652-0.820)$ & $0.714^{* * * *}(0.638-0.799)$ & $0.728^{* * *}(0.650-0.816)$ \\
\hline Some college & $0.568^{* * *}(0.479-0.673)$ & $0.586^{* * * *}(0.492-0.698)$ & $0.564^{* * * *}(0.475-0.671)$ & $0.582^{* * *}(0.489-0.693)$ \\
\hline Associates & $0.633^{* * * *}(0.502-0.798)$ & $0.652^{* * * *}(0.514-0.826)$ & $0.627^{* * * *}(0.498-0.791)$ & $0.646^{* * *}(0.510-0.817)$ \\
\hline Bachelors & $0.449^{* * *}(0.381-0.529)$ & $0.469^{* * * *}(0.396-0.555)$ & $0.448^{* * * *}(0.379-0.530)$ & $0.469^{* * *}(0.395-0.556)$ \\
\hline Masters & $0.341^{* * * *}(0.257-0.453)$ & $0.352^{* * * *}(0.264-0.470)$ & $0.338^{* * * *}(0.253-0.452)$ & $0.360^{* * *}(0.269-0.483)$ \\
\hline Graduate & $0.203^{* * *}(0.130-0.317)$ & $0.215^{* * * *}(0.137-0.336)$ & $0.202^{* * * *}(0.129-0.317)$ & $0.219^{* * *}(0.140-0.344)$ \\
\hline Metropolitan area & $1.025(0.850-1.236)$ & $1.009(0.836-1.218)$ & $1.006(0.834-1.213)$ & $0.998(0.827-1.205)$ \\
\hline \multicolumn{5}{|c|}{$\begin{array}{l}\text { U.S. Region of Residence: (reference category: Northeastern } \\
\text { Region) }\end{array}$} \\
\hline Midwest & $0.832^{* *}(0.705-0.983)$ & $0.857^{*}(0.720-1.020)$ & $0.841^{* *}(0.713-0.994)$ & $0.862 *(0.724-1.027)$ \\
\hline South & $0.684^{* * *}(0.601-0.778)$ & $0.703^{* * * *}(0.615-0.804)$ & $0.687^{* * * *}(0.604-0.781)$ & $0.701^{* * *}(0.613-0.802)$ \\
\hline West & $0.915(0.815-1.026)$ & $0.946(0.832-1.075)$ & $0.929(0.827-1.044)$ & $0.950(0.835-1.081)$ \\
\hline \multicolumn{5}{|l|}{$\begin{array}{l}\text { Country of origin } \\
\text { characteristics }\end{array}$} \\
\hline Gini index greater than U.S. & $0.762^{* * * *}(0.651-0.892)$ & $0.698^{* * * *}(0.590-0.825)$ & $0.743^{* * * *}(0.627-0.880)$ & $0.641^{* * *}(0.529-0.776)$ \\
\hline $\operatorname{Ln}(\mathrm{GPD})$ & & & $0.899^{*}(0.805-1.004)$ & $0.828^{* * *}(0.735-0.933)$ \\
\hline Ln (life expectancy at birth) & & & $1.063(0.325-3.483)$ & $1.552(0.371-6.496)$ \\
\hline $\begin{array}{l}\text { Combined gross enrollment ratio } \\
\text { in education }\end{array}$ & & & $1.000(0.991-1.008)$ & $1.009 *(0.999-1.018)$ \\
\hline \multicolumn{5}{|c|}{$\begin{array}{l}\text { Region of birth fixed effects (reference category: Central } \\
\text { America) }\end{array}$} \\
\hline North America & & $0.335^{* * * *}(0.186-0.603)$ & & $0.305^{* * *}(0.164-0.567)$ \\
\hline Africa & & $1.300(0.780-2.169)$ & & $1.283(0.691-2.380)$ \\
\hline South America & & $0.786^{* *}(0.640-0.966)$ & & $0.709^{* * *}(0.566-0.889)$ \\
\hline West Indies & & $1.253^{* *}(1.017-1.545)$ & & $1.259^{* *}(1.023-1.550)$ \\
\hline
\end{tabular}




\begin{tabular}{|c|c|c|c|c|}
\hline \multirow[t]{2}{*}{ Variables } & $\underline{(1)}$ & $\underline{(2)}$ & (3) & \multirow[t]{2}{*}{ (4) } \\
\hline & \multicolumn{3}{|c|}{ Odds ratios from logistic regression models of fair/poor health } & \\
\hline Europe & & $0.664^{* *}(0.466-0.948)$ & & $0.629^{* *}(0.430-0.919)$ \\
\hline Asia & & $0.721^{* *}(0.526-0.989)$ & & $0.643^{* * * *}(0.463-0.892)$ \\
\hline Other immigrants & & $1.754(0.523-5.879)$ & & $1.716(0.505-5.827)$ \\
\hline Constant & $0.040^{* * *}(0.018-0.087)$ & $0.058^{* * *}(0.025-0.132)$ & $0.091(0.001-8.297)$ & $0.029(0.000-7.083)$ \\
\hline Observations & 35620 & 35620 & 35620 & 35620 \\
\hline \multicolumn{5}{|l|}{$* * * * 0.01$} \\
\hline \multicolumn{5}{|l|}{$* * x<0.05$} \\
\hline${ }^{*}<0.1$ & & & & \\
\hline
\end{tabular}

Robust $Z$ statistics in parentheses. Source: Individual level data are taken from the 1996, 1998, 2000, 2002, 2004, 2006, and 2008 March Current Population Surveys for immigrants between the ages of 25 and 64. Country-of-origin characteristics are taken from the United Nations Human Development Programme's 2009 Human Development Reports. All models also include controls for the survey year of each observation. 


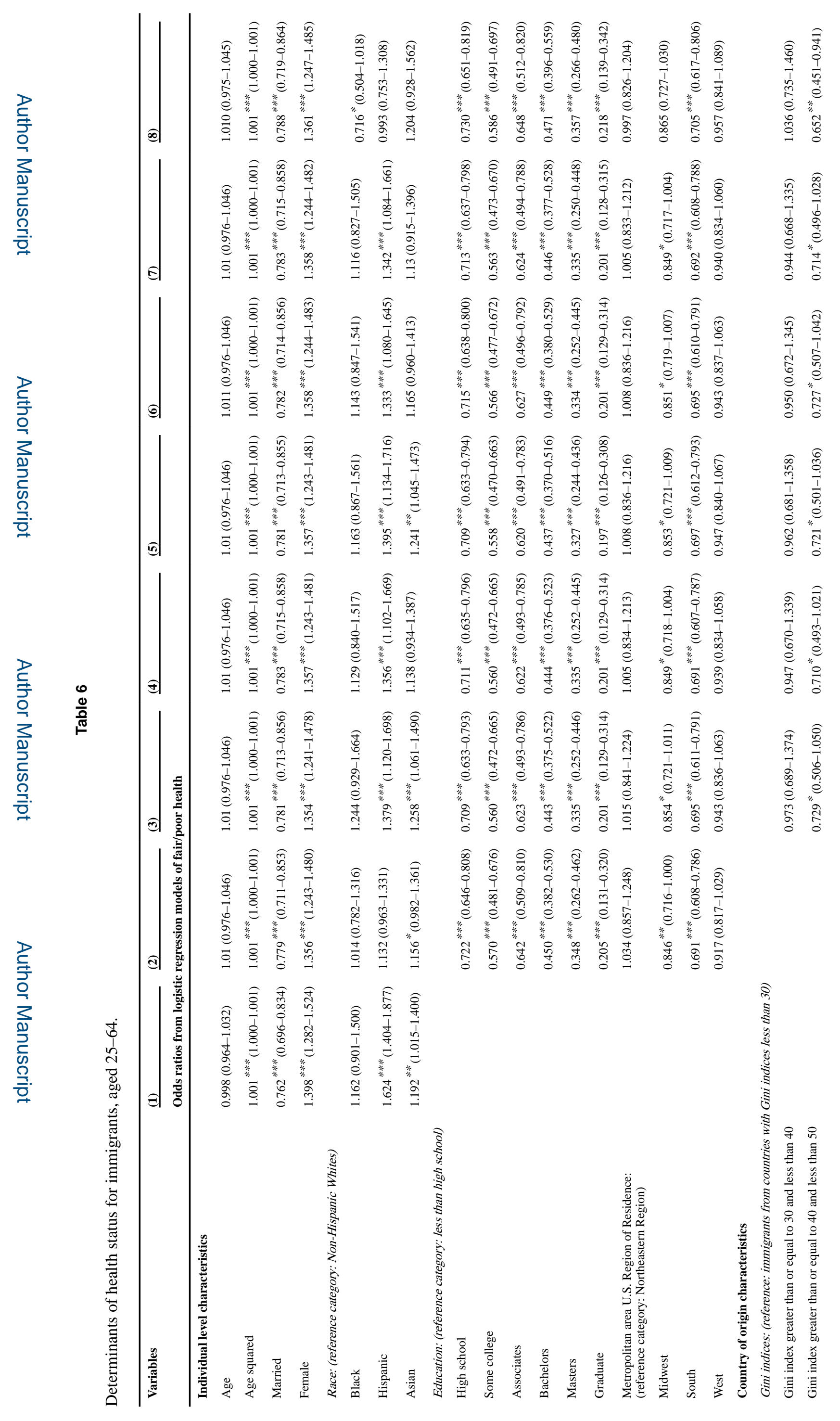




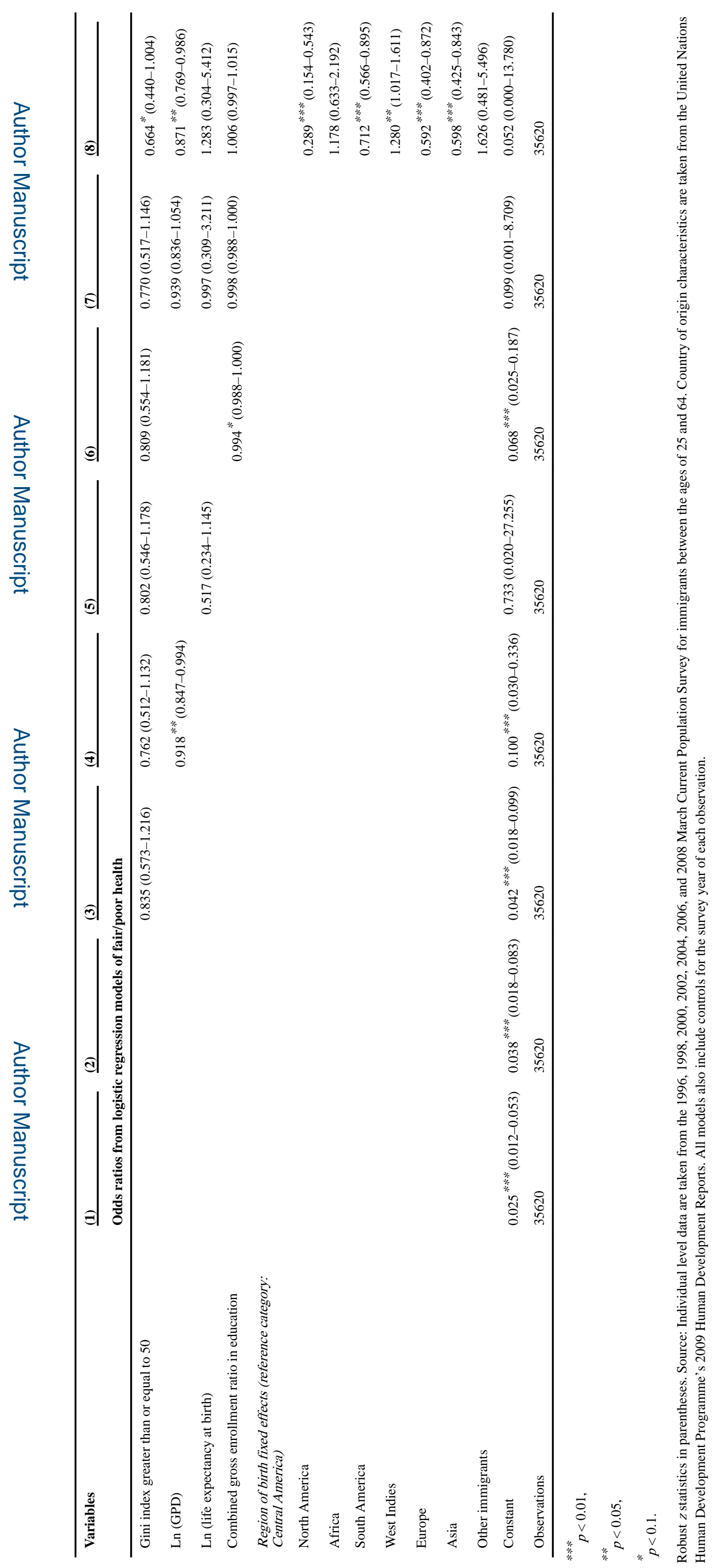

